\title{
July Effect in Obstetric Outcomes
}

\author{
Megan Pagan', Ann Marie Mercier', Dayna Whitcombe', Songthip T Ounpraseuth², \\ Everett F Magann $\mathbb{D}^{\prime}$, Amy Phillips'
}

'Department of Obstetrics \& Gynecology, University of Arkansas for Medical Sciences, Little Rock, AR, 72205, USA; ${ }^{2}$ Department of Biostatistics, University of Arkansas for Medical Sciences, Little Rock, AR, 72205, USA

Correspondence: Everett F Magann, Department of Obstetrics \& Gynecology, Division of Maternal Fetal Medicine, University of Arkansas for Medical Sciences, 430I W. Markham Street Slot \#5I8, Little Rock, AR, 72205, USA, Tel + I-50I-686-8345, Email efmagann@uams.edu

Objective: The July effect represents the month when interns begin residency and residents advance with increased responsibility. This has not been well studied in Obstetrics and Gynecology residencies and no study has been conducted evaluating obstetric outcomes. The purpose of this study was to evaluate the July effect on obstetric outcomes. Women who delivered between July and September (quarter 1) were compared to those delivering between April and June (quarter 4).

Methods: This retrospective cohort study compared outcomes of deliveries between quarter 1 and quarter 4 from 2017 to 2020 . Outcomes evaluated were postpartum length of stay (LOS), postpartum readmission, wound complication, wound infection, blood transfusion, estimated blood loss, 3rd and 4th degree lacerations, 5 min APGAR scores, and cesarean delivery rates.

Results: There were 3693 deliveries in quarter 1 and 3107 deliveries in quarter 4 . There was a higher incidence Of wound infection during the April-June period $(\mathrm{N}=21 ; 0.68 \%)$ compared to July-September $(\mathrm{N}=10 ; 0.27 \% ; \mathrm{p}=0.0135)$. Although LOS for both periods were the same, the average postpartum LOS during July-September was slightly longer than April-June $(1.7$ days; SD $=1.1$ vs 1.6 days; $\mathrm{SD}=1.2 ; \mathrm{p}=0.0026$ ). All other pregnancy outcomes were similar between the two groups.

Conclusion: Overall, the July effect is minimal on obstetric complications. However, LOS between July and September may differ because all residents are less experienced in quarter 1. Wound infection rates were higher in April-June, perhaps because new PGY-1s went from assisting to primary on cesarean surgeries starting in the 4th quarter of the year.

Keywords: July effect, obstetrics, interns, obstetric outcomes, residents

\section{Introduction}

The July effect or July phenomenon represents the time of year when new interns begin residency in hospitals across the country and current residents advance in their training with increased responsibility. The theory of the "July Effect" is that quality of care and patient safety may be negatively impacted during this time period. ${ }^{1}$ Multiple studies suggest a possible correlation between this time period and poorer patient outcomes. ${ }^{2-4}$ Residency training facilities have a dual responsibility to provide a safe and effective learning environment for resident physicians while not compromising patient care. Practical hands-on training is a critical part of resident education in surgical subspecialties like obstetrics and gynecology. This often begins on the first day of the first year of their residency, July 1st. Understanding whether this effect exists in obstetrics and, if so, which patient outcomes are affected is important for educators and will allow them to target these areas of training for residents.

The July Effect has not been well studied in obstetrics and gynecology (OBGYN) residencies. In one study of the July Effect in new medical residents, Phillips et al found a $10 \%$ increase in fatal medication errors during the month of July. ${ }^{5}$ There have also been some studies in surgical specialties which appear to contradict the presence of the July Effect. ${ }^{5-8}$ A meta-analysis and systematic review by Young et al reported increased mortality; although, heterogeneity likely affected the results. ${ }^{3}$ This study was not specific to one specialty and the studies included were $31 \%$ Medical, $49 \%$ surgical, and $21 \%$ of the studies including both medical and surgical.

Recent studies that have examined specific delivery outcomes in the obstetric population are limited. A study from 2017 examined the July Effect with resident duty hour restriction on peripartum outcomes. This study found that mothers 
delivering at teaching hospitals in July and August had more peripartum complications before, but not after, resident work hour reform (RR 1.03, 95\% CI 1.01-1.05). ${ }^{9}$ The purpose of this study was to evaluate the July effect on obstetric outcomes at our institution for women who delivered between the months of July through September (quarter 1) with those women who delivered from April through June (quarter 4).

\section{Methods}

This was a retrospective cohort study of delivery outcomes of all women who delivered in quarter 1 (July - September) compared to all women delivering in quarter 4 (April - June) in the years 2017-2020. The Institutional Review Board approved this study.

Patients were excluded if data from their delivery admission was missing (no estimated blood loss or BMI recorded). Six thousand eight hundred patients were included. This retrospective data was collected from the university electronic medical record system.

The primary study outcome examined was wound infections. The secondary outcomes included: postpartum length of stay, postpartum readmission, wound complication, blood transfusion, estimated blood loss, 3rd and 4th degree lacerations (OASIS), 5 min APGAR scores, and cesarean delivery rates.

Descriptive statistics were used to describe the study population and maternal and infant outcomes stratified by delivery periods (April-June vs July-September). Frequencies and percentages were reported for categorical measures while means and standard deviations were computed for continuous measures. For skewed data, we reported medians along with 25th and 75th percentiles. To evaluate differences across the delivery periods among maternal and infant measures, two-sample $t$-test or Wilcoxson rank-sum test was used, as appropriate, for continuous variables while chisquare or Fisher's exact was used for categorical measures. Next, multivariable generalized linear models with appropriate link functions (ie, identity for normal; log for Poisson; logit for Binomial) were used to determine associations between delivery periods with outcomes while adjusting for maternal characteristics. All analyses were performed using SAS 9.4 (SAS Institute, Cary, NC) based on a two-sided test with significance level of 0.05 . Given the exploratory nature of these analyses and to protect against the inflation of type II error, no p-value adjustment was performed despite having multiple comparisons.

\section{Results}

We identified 6800 patients overall who delivered at UAMS between the months of July-September $(\mathrm{N}=3693)$ and April-June ( $\mathrm{N}=3107)$ for the years 2017-2020. The average maternal age was $27.5(\mathrm{SD}=6.0)$ years of age with a mean BMI of 33.5 ( $\mathrm{SD}=8.1)$. There were no statistical differences across the two delivery periods in terms of maternal age, BMI, or parity (see Table 1). However, there was a difference in the distribution of race/ethnicity between the periods

Table I Maternal Demographics

\begin{tabular}{|l|c|c|c|}
\hline Measure & April-June & July-September & p-value \\
\hline Age, mean \pm SD & $27.38 \pm 6.07$ & $27.5 I \pm 5.92$ & 0.3516 \\
\hline Race, N (\%) & & & 0.0072 \\
\hline White & $1425(45.86 \%)$ & $1554(42.08 \%)$ & \\
\hline Black & $1037(33.38 \%)$ & $1326(35.91 \%)$ & \\
\hline Other & $645(20.76 \%)$ & $813(22.01 \%)$ & $0.5208^{*}$ \\
\hline Parity, median [QI, Q3] & $1[0,2]$ & $1[0,2]$ & 0.0622 \\
\hline BMI, mean \pm SD & $33.27 \pm 7.9$ & $33.64 \pm 8.23$ & \\
\hline
\end{tabular}

Note: *Denote $\mathrm{p}$-value from Wilcoxon rank-sum test; $\mathrm{QI}=25$ th percentile; $\mathrm{Q} 3=75$ th percentile. 
Table 2 Maternal and Infant Outcomes

\begin{tabular}{|c|c|c|c|}
\hline Measure & April-June & July-September & p-value \\
\hline Postpartum LOS, median [QI, Q3] & $\mathrm{I}[\mathrm{I}, 2]$ & $\mathrm{I}[\mathrm{I}, 2]$ & $0.0026^{*}$ \\
\hline EBL, median [QI, Q3] & $400[200,800]$ & $400[250,800]$ & $0.2195^{*}$ \\
\hline Readmission, N (\%) & $|4|(4.54 \%)$ & 156 (4.22\%) & 0.5281 \\
\hline Wound complication, N (\%) & 53 (1.7I\%) & $62(1.68 \%)$ & 0.9315 \\
\hline Wound infection, N (\%) & $21(0.68 \%)$ & $10(0.27 \%)$ & 0.0135 \\
\hline \multicolumn{4}{|l|}{ Blood transfusion, $\mathrm{N}(\%)$} \\
\hline RBC, N (\%) & $109(3.51 \%)$ & 103 (2.79\%) & 0.0892 \\
\hline FFP, N (\%) & II (0.35\%) & $13(0.35 \%)$ & 0.9888 \\
\hline Platelets, N (\%) & $6(0.19 \%)$ & $6(0.16 \%)$ & $0.7800 * *$ \\
\hline 3rd and 4th degree lacerations, N (\%) & II (0.35\%) & $8(0.22 \%)$ & 0.2849 \\
\hline Cesarean delivery, N (\%) & 1223 (39.36\%) & $1540(4 \mid .70 \%)$ & 0.0506 \\
\hline 5 min APGAR, median [QI, Q3] & $9[8,9]$ & $9[8,9]$ & $0.3902 *$ \\
\hline
\end{tabular}

Notes: *Denote $\mathrm{p}$-value from Wilcoxon rank-sum test; $\mathrm{Q} I=25$ th percentile; $\mathrm{Q} 3=75$ th percentile. **Denote $\mathrm{p}$-value from Fisher's exact test.

$(\mathrm{p}=0.0072)$ with a slightly higher number of Caucasian women delivering during the April-June period $(46 \%)$ compared to the July-September period (42\%).

Among the various maternal and infant outcomes, only postpartum hospital length of stay (LOS) and surgical wound infection were statistically significant across the two delivery periods (see Table 2). More specifically, there was a higher incidence of wound infection during the April-June period $(\mathrm{N}=21 ; 0.68 \%)$ compared to July-September $(\mathrm{N}=10$; $0.27 \% ; \mathrm{p}=0.0135)$. While the median postpartum LOS for the two delivery periods were the same, the average postpartum LOS during July-September was slightly longer than during the April-June (1.7 days; $\mathrm{SD}=1.1$ vs 1.6 days; $\mathrm{SD}=1.2 ; \mathrm{p}=0.0026)$ While not statistically significant at the 0.05 level, there were more cesarean deliveries during the July-September period compared to the April-June quarter ( $42 \%$ vs $39 \%$; $=0.051)$. In the adjusted analysis, there remained a statistical difference in the odds of having a wound infection among deliveries during the April-June period compared to the July-September period after accounting for maternal age, BMI, race, and parity (adjusted OR $=2.6$; 95\% CI: $1.2-5.5 ; \mathrm{p}=0.0145$ ). As expected, the adjusted analysis for cesarean deliveries was not statistically significant (adjusted OR $=1.08 ; 95 \%$ CI: $0.98-1.20 ; \mathrm{p}=0.140$ ). Given that postpartum LOS was skewed, we treated the LOS as a count measure. Therefore, we used a Poisson regression model to examine the relationship between delivery periods with LOS while adjusting for maternal factors. After accounting for age, BMI, race, and parity, the postpartum LOS outcome remained statistically significant across the two delivery periods $(p=0.0159)$ although this length of stay between the 2 time periods is not clinically significant. The expected LOS during the July-September period is 1.66 days compared to 1.59 days for April-June.

\section{Discussion}

Overall, we observed that women delivering at this academic institution did not experience worse obstetric outcomes or a July Effect when delivering July through September compared to women delivering during April through June. Although our results found a slightly longer average postpartum LOS during the July-September than the April-June quarter, the difference was only 0.1 days and is not clinically significant. Although not statistically significant, there were more cesarean deliveries during the July-September period compared to April-June. The effects seen in the length of stay and the cesarean delivery rate may be because the experience of the entire residency is one year less than the 
residents who just finished or advanced by a year in the proceeding April to June quarter. We also observed an unexpected statistically significant higher incidence of wound infection during the April-June period compared to July-September. This would seem to negate the July effect for wound infections; however, the obstetric surgery done from July through September may be performed by the PGY-2 level resident with the PGY-1 resident assisting either the attending or chief resident. The PGY-1 level resident may not be the primary on obstetrical surgical procedures until late in the second half of their first year when the attending or chief/upper-level resident would assist the PGY-1 with obstetrical surgery. Although this is not true for all residency programs, this may have had an influence on the increased number of wound infections in the fourth quarter of the year.

The July Effect has been inadequately studied in obstetric populations. A study by Myles reviewed 7814 delivery records from a single hospital and found no increased complication rates in the month of July, except for an increased rate of chorioamnionitis. ${ }^{9}$ One study was identified that examined the July Effect with resident duty hour restriction on peripartum outcomes. This study found that mothers delivering at teaching hospitals in July and August had more peripartum complications before, but not after, resident work hour reform (RR 1.03, 95\% CI 1.01-1.05). ${ }^{10}$ The largest multi-institution study investigating obstetric outcomes was published in 2007. This showed no increased rate of operator-dependent complications of Medicaid patient deliveries at teaching hospitals nationwide in the month of July. ${ }^{11}$ In their 10 year study, Moaddab et al recently concluded that there was no July phenomenon for either maternal or fetal mortality in the United States. ${ }^{12}$ No recent study was identified that examined specific delivery outcomes in the obstetric population.

A 2018 study by Mastroyannis et al examined gynecologic surgery outcomes in benign and oncologic cases and negated the July Effect in that there was no increase in post-operative complications. This study did find that the first academic quarter of benign surgeries was associated with an increased length of stay and re-operation; whereas, only length of stay was increased in oncologic cases during this time period. ${ }^{13}$ Another study by Varma et al in 2018 found no correlation in adverse patient outcomes, length of stay, or readmissions for patients undergoing hysterectomy in JulySeptember. ${ }^{14}$ Other studies have also examined general adverse events and outcomes in July vs other months in academic institutions. A 1995 article by Shulkin found no support for a "July Phenomenon" in terms of quality of clinical care but house officers were found to be more likely to have poor documentation practices earlier in the academic year. ${ }^{15}$

Limitations to a July Effect study include: inability to quantify resident involvement in deliveries, outcomes are dependent on interdisciplinary care teams (anesthesia, nurses, midwives, etc.), the possibility of increased attending supervision and intervention during the time period of July-September, varying techniques used intraoperatively, and underreporting of diagnosis codes. Coding decisions and methodology are provider dependent and could not be controlled for in this study.

A future study is being discussed to further clarify our finding by the year level of the residents involved to further assess differences in outcomes. Additional studies should be considered on a national basis for assessment of obstetric outcomes by year level of the resident and quarter of training in those years.

\section{Conclusion}

Training facilities have a dual responsibility to provide a safe and effective learning environment for resident physicians while not compromising patient care. Practical hands-on training during residency is essential in obstetrics and gynecology and begins on the first day of the first year of residency. Our study did find that some obstetric outcomes were worse in the 1st quarter of the academic year, suggesting that the July effect may be due to less experience by the entire residency as they move up in rank and responsibility by year of training. The 4th quarter results of the incoming residents were observed to be more frequently related to operative obstetrics later in the academic year. This is suggested by less wound infection rates during quarter 1 than in quarter 4 . One possible reason for the observed increased wound infection rate may be that first year resident participation in surgical procedures is more limited in the first quarter to that of assistant rather than the primary surgeon but this is not true in all residency programs. Their participation as a primary surgeon increases considerably during the second half of their first year, particularly during the 4th quarter. There may also be more vigilant supervision by faculty in the first quarter of the year because new first year residents are starting their residency. More study is needed on training by year and by responsibility transition. 


\section{Disclaimer}

The opinions or assertions contained herein are the private views of the authors and are not to be construed as the official policy of the Department of the Army, Department of Defense, or the US Government.

\section{Institutional Review Board Approval}

The Institutional Review Board of the University of Arkansas for Medical Sciences approved this study (\#261744). Waivers of consent and HIPAA authorization were requested and granted. The rationale for the waivers was that this study is no more than minimal risk to the subjects and the research involves no procedures for which written consent is normally required outside of the research context. This research study on humans has been performed in accordance with the principles stated in the Declaration of Helsinki.

\section{Acknowledgments}

We thank Donna Eastham, BA for her assistance in editing, formatting, and submission.

\section{Funding}

No funding or financial support was received for this work.

\section{Disclosure}

Dr Everett F Magann writes the chapter in UptoDate on the ultrasound assessment of amniotic fluid volume oligohydramnios. The authors report no other conflicts of interest related to this work.

\section{References}

1. Petrilli CM, Del Valle J, Chopra V. Why July matters. Acad Med. 2016;91(7):910-912. doi:10.1097/acm.0000000000001196

2. Phillips DP, Barker GE. A July spike in fatal medication errors: a possible effect of new medical residents. J Gen Intern Med. 2010;25(8):774-779. doi:10.1007/s11606-010-1356-3

3. Young JQ, Ranji SR, Wachter RM, Lee CM, Niehaus B, Auerbach AD. "July effect": impact of the academic year-end changeover on patient outcomes: a systematic review. Ann Intern Med. 2011;155(5):309-315. doi:10.7326/0003-4819-155-5-201109060-00354

4. Wen T, Attenello FJ, Wu B, Ng A, Cen SY, Mack WJ. The July effect: an analysis of never events in the nationwide inpatient sample. J Hosp Med. 2015;10(7):432-438. doi:10.1002/jhm.2352

5. McDonald JS, Clarke MJ, Helm GA, Kallmes DF. The effect of July admission on inpatient outcomes following spinal surgery. J Neurosurg Spine. 2013;18(3):280-288. doi:10.3171/2012.12.Spine12300

6. Ravi P, Trinh VQ, Sun M, et al. Is there any evidence of a "July effect" in patients undergoing major cancer surgery? Can J Surg. 2014;57 (2):82-88. doi:10.1503/cjs.002713

7. Bohl DD, Fu MC, Golinvaux NS, Basques BA, Gruskay JA, Grauer JN. The "July effect" in primary total hip and knee arthroplasty: analysis of 21,434 cases from the ACS-NSQIP database. J Arthroplasty. 2014;29(7):1332-1338. doi:10.1016/j.arth.2014.02.008

8. Karipineni F, Panchal H, Khanmoradi K, Parsikhia A, Ortiz J. The "July effect" does not have clinical relevance in liver transplantation. $J$ Surg Educ. 2013;70(5):669-679. doi:10.1016/j.jsurg.2013.04.012

9. Peltan ID, Brown CE, Burke AK, Chow EJ, Rowhani-Rahbar A, Crull MR. The July effect on maternal peripartum complications before and after resident duty hour reform: a population-based retrospective cohort study. Am J Perinatol. 2017;34(8):818-825. doi:10.1055/s-0037-1598244

10. Myles TD. Is there an obstetric July phenomenon? Obstet Gynecol. 2003;102(5 Pt 1):1080-1084. doi:10.1016/j.obstetgynecol.2003.08.001

11. Ford AA, Bateman BT, Simpson LL, Ratan RB. Nationwide data confirms absence of 'July phenomenon' in obstetrics: it's safe to deliver in July. J Perinatol. 2007;27(2):73-76. doi:10.1038/sj.jp.7211635

12. Moaddab A, Clark SL, Dildy GA, Sangi-Haghpeykar H. The July phenomenon in current obstetric practice. Am J Obstet Gynecol. 2017;217 (4):487-488. doi:10.1016/j.ajog.2017.05.063

13. Mastroyannis SA, Buckingham L, Brensinger C, Latif N, Haggerty A, Ko E. Is there a "July effect" in oncologic and benign gynecologic surgery? [17Q]. Obstet Gynecol. 2018;131:189S. doi:10.1097/01.Aog.0000533230.37014.75

14. Varma S, Mehta A, Hutfless S, Stone RL, Wethington SL, Fader AN. Is there evidence of a July effect among patients undergoing hysterectomy surgery? Am J Obstet Gynecol. 2018;219(2):176.e1-.e9. doi:10.1016/j.ajog.2018.05.033

15. Shulkin DJ. The July phenomenon revisited: are hospital complications associated with new house staff? Am J Med Qual. $1995 ; 10(1): 14-17$. doi: $10.1177 / 0885713 \times 9501000104$ 


\section{Publish your work in this journal}

The International Journal of Women's Health is an international, peer-reviewed open-access journal publishing original research, reports, editorials, reviews and commentaries on all aspects of women's healthcare including gynecology, obstetrics, and breast cancer. The manuscript management system is completely online and includes a very quick and fair peer-review system, which is all easy to use. Visit http://www. dovepress.com/testimonials.php to read real quotes from published authors.

Submit your manuscript here: https://www.dovepress.com/international-journal-of-womens-health-journal 